\title{
Effect of Temperature and Number of Individuals of Common Coot, Fulica atra (Gruiformes: Rallidae) on Grouping and Dispersal on the Sapanca Lake Surface, Turkey
}

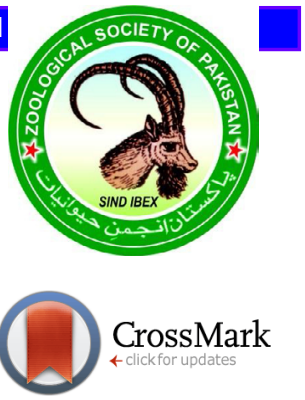

\author{
Ali Uzun* and Bilgenur Yasa \\ Department of Biology, Arts and Science Faculty, Sakarya University, Sakarya, Turkey
}

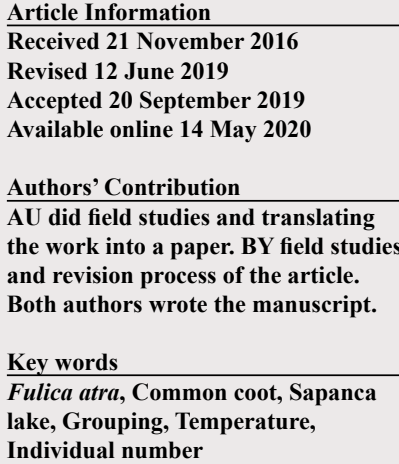

\section{INTRODUCTION}

$\mathrm{C}$ Tommon coot, Fulica atra, is found in Asia, Europe, and Australia. It is native in the region where it lives. Also it is resident in Sapanca Lake, Turkey (Uzun, 2010). They can form large groups in wetland habitats according to the size of wetlands. Some factors that affect the preference for wetland areas include vegetation structure, food availability, resting places, breeding grounds, and provision of shelter from predators and competitors (McNally, 1990; Leisler, 1992; SebastianGonzalez et al., 2010). Calder and King (1974), Kendeigh et al. (1977) studied the birds' physiological and behavioral responses that change in response to the ambient temperature. Moreover, habitat selection and migratory strategies are mainly shaped by climatic conditions (Brent et al., 1985). Coot behavior (including activity patterns or winter behavior) is considered inexplicable by Cramp and Simmons (1980). For this reason, the data about baseline behaviors are essential to better understand the ecology of the species. Therefore, the grouping and dispersal behavior of the common coot group on the Sapanca lake was analyzed in this study. The effect of temperature and the total number of individuals on these behaviors was studied.

\footnotetext{
* Corresponding author: aliuzun@sakarya.edu.tr 0030-9923/2020/0005-1761 \$ 9.00/0

Copyright 2020 Zoological Society of Pakistan
}

\section{MATERIALS AND METHODS}

The study was conducted from October 2015 to April 2016 at Sapanca Lake (Turkey). Twenty-five field visits were conducted during the period: three (3) in October, seven (7) in November, six (6) in December, three (3) in January, five (5) in February, and one (1) in March. Each field study was conducted from 14.00 to 18.00 hours (total observation time 100 hours). Hence, a standard was achieved for observing the behavior of the individuals on the lake surface and evaluation of the data. Observations were made by the naked eye and using Nikon (10x40mm) binoculars. The number of individuals was estimated during the field trip and confirmed by the images taken by a Canon $550 \mathrm{D}$ camera and Sigma $150-500 \mathrm{~mm}$ tele objective. The distance between groups and dispersal distance of individuals was determined by the scaled images and the UTM coordinate system. Etrex 20 GPS (Garmin) was used to obtain coordinates. The temperature was measured by PCE-22. A distance of at least 10 meters between two groups was taken into account while determining and counting the groups. Dispersal distance was detected by considering the individuals at extreme points from the shore towards the interior of the lake. Distance from the shore was recorded on the lake surface as the distance between the nearest individual to the shore and the zero point of the shore.

\section{Study area}

Sapanca Lake was formed by tectonic subsidence. 
The lake covers 42-44 square kilometers $\left(\mathrm{km}^{2}\right)$ area at an an altitude of $30 \mathrm{~m}$. The eastern end of the lake is $5 \mathrm{~km}$ from the Sakarya River, and the western end $20 \mathrm{~km}$ from Izmit Gulf. The length of the lake is $16 \mathrm{~km}$, the widest part is $6 \mathrm{~km}$ and the coastline is $39 \mathrm{~km}$. The deepest point of the lake is $52 \mathrm{~m}$. The Samanli, Kayinli, and Keramali Mountains, the main watershed of the lake, covered with forests are located south of the lake. The lake is fed by small rivulets coming from these mountains (Keci Stream, Istanbul Stream, Mahmudiye Stream, Kurucay Stream, Karacay Stream, Balikhane Stream, Maden Stream, and Arifiye Stream) and from sources in the lake bottom. Lake water discharges into the Sakarya River with Cark Water from the eastern end (Uzun, 2010). The western and eastern ends of the lake with the high density of bird population are covered with large reeds. The lake is under intense human pressure due to residential housing, industry, tourism, and transportation.

\section{Statistical analysis}

Shapiro-Wilk normality tests were done to determine whether the quantitative (numerical) variables like temperature, total individual number, and dispersal distance were distributed normally. At the end of the analysis it was decided that temperature and total number of individual's variables to be distributed normally and number of groups, average number of individuals in the groups, dispersal distance variables not to be distributed normally. Both parametric (Pearson correlation) and nonparametric (Spearman rho correlation) test were used.

\section{RESULTS}

The Sapanca Lake is an important wetland for the coot. Coots gather in the form of large groups especially in the eastern and western parts of the lake due to widespread reed areas in these regions. The total number of individuals recorded during the study, from 25 different observation points was 135,450 . The highest number of individuals $(11,500)$ was recorded on November 25, 2015, and the lowest number (80) was recorded on February 29, 2016. During the study, individual numbers varied from eighty (80) to 11,500 . Common coot entered the breeding season in March. At the beginning of this period, individuals preferred large reed areas around the lake. Therefore, individuals were not recorded on the lake surface during the breeding season. The temperature varied between $-1{ }^{\circ} \mathrm{C}$ and $26^{\circ} \mathrm{C}$ throughout the study. The lowest temperature (-1 ${ }^{\circ} \mathrm{C}$ ) was recorded on December 31, 2015, and the highest $\left(26^{\circ} \mathrm{C}\right)$ on February 29, 2016 (Fig. 1).

The correlation of temperature and total number of individuals, variations of number of group, average number of individuals in the group and dispersal distance were calculated. At first, Shapiro-Wilk normality test was applied. It was seen that the temperature and total number of individuals were distributed normally; while the variations of number of group, average number of individuals in the group and dispersal distance were did not distributed normally (Shapiro-Wilk $\mathrm{p}<.05$ ).

There is no significant relation between temperature and total number of individuals $(r=.03, p>.05)$. In other words total number of individuals did not show changes dependent on temperature.

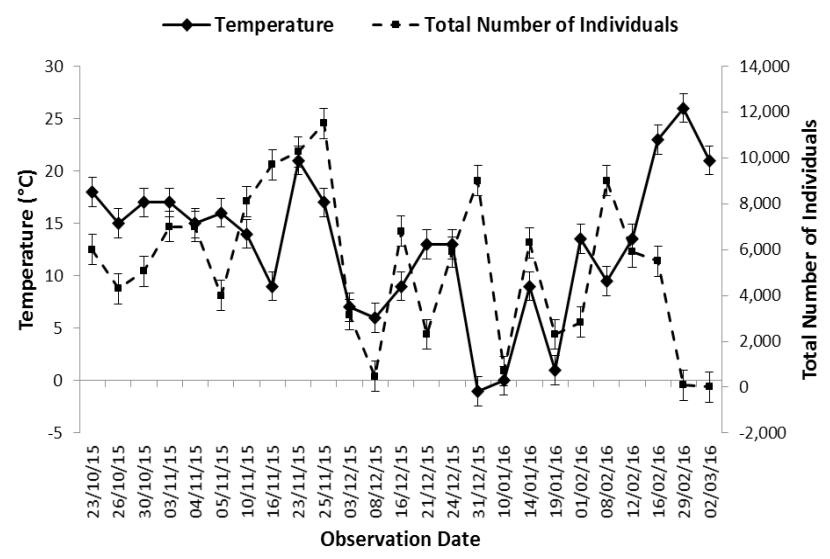

Fig. 1. Temperature and total number of individuals.

Temperature and number of groups showed negative highly non-significant relationship $(\mathrm{r}=-.76, \mathrm{p}<.01)$. In other words, temperature affected the number of groups. The number of group decreased with increasing temperature and the number of group increased with decreasing temperature. However, there was no significant relationship between temperature and average number of individuals in groups $(r=.07, \mathrm{p}>.05)$ and dispersal distance (although individuals remained in coastal areas at low temperatures and spread up to 300 meters in the lake at high temperatures, Fig. 2) $(r=-.23, p>.05)$. In other words, the temperature did not affect average number of individuals in groups and dispersal distance.

The dispersal pattern of individuals forming coot groups on the lake surface varied during the day (during observation hours). Feeding, breeding (during end of February-beginning of March), and activity behavior were observed during the day. The group forming and dispersal on the lake occurred due to two main factors: security and temperature. Individuals met and formed groups with in different numbers when disturbed by birds of prey and fishermen fishing on the lake in boats. The movement pattern was in the form of going away and getting involved with the nearest existing group. This type of distribution 
appeared depending on the instant impact. When the threat disappeared, individuals returned to the normal distribution pattern in a short time. Temperature, on the other hand, was permanently effective and thus it mainly determined the dispersal pattern of individuals on the lake. The threshold temperature for group forming was $10 \mathrm{C}^{\circ}$ (Fig. 3). On February 1, 2016, three groups were observed on the lake surface although the temperature was $13.5^{\circ} \mathrm{C}$. This occurrence was an exception; due to strong wind, the individuals had to gathered in the coastal strip.

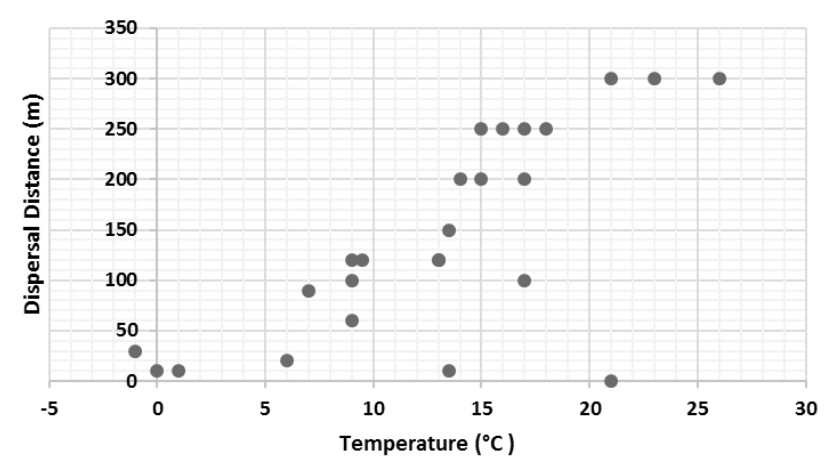

Fig. 2. The relationship between temperature and dispersal distance.

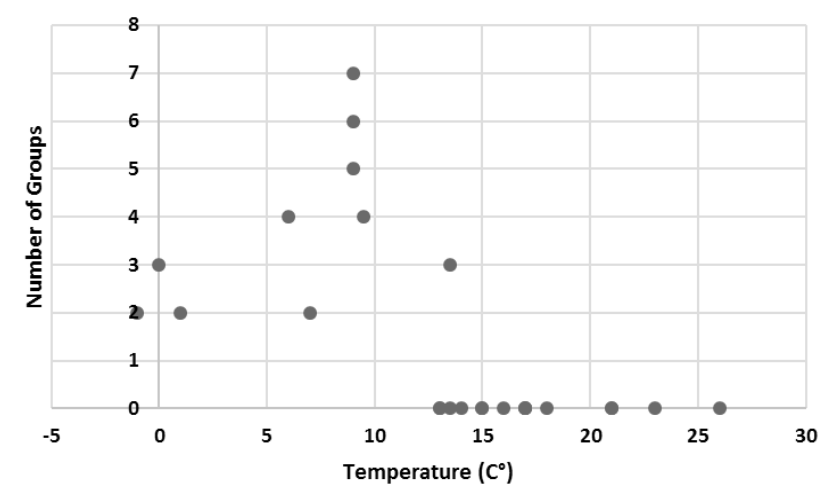

Fig. 3. The relationship between temperature and group number.

Also, relation of total number of individuals, average number of individuals in groups and dispersal distance were evaluated. At first, Shapiro-Wilk normality test was applied. According to results of the test, it was seen that total number of individuals was distributed normally; whereas the number of groups, average number of individuals in groups and dispersal distance were not distributed normally (Shapiro-Wilk $\mathrm{p}<.05$ ). According to analysis of Spearman rho correlation, no significant relationship was found between total number of individuals and number of groups. In other words, the number of groups did not affect the total number of individuals (Table I). Similarly, no significant relation was not found between total number of individuals and dispersal distance $(r=.36, \mathrm{p}>.05)$. Despite that, total number of individuals and average number of individuals in groups showed positive highly significant relationship (Table I, $\mathrm{r}=.85, \mathrm{p}<.01$ ).

Table I. Relationship between total number of individuals and number of group, average number of individuals in groups and dispersal distance (Spearman rho correlation).

\begin{tabular}{lll}
\hline & $\begin{array}{l}\text { Total number } \\
\text { of individuals }\end{array}$ & $\mathbf{p}$ \\
\hline Total number of individuals & & .861 \\
Number of groups & .04 & .002 \\
Av. number of individuals in groups & $.85^{* *}$ & .081 \\
Dispersal distance (m) & .36 & \\
${ }^{* *}: \mathrm{p}<.01$. & &
\end{tabular}

\section{DISCUSSION}

Behavior types and density of the coot groups are divided into two groups: breeding and non-breeding period behaviors. Intense competition in the reproductive period determines the behavior carried out individually and in the community. Environmental factors are the main determinants in the non-reproductive period (Zhang et al., 2011). Temperature has a significant impact on bird behavior (individual or in the community) (Irwin and O'Halloran, 1997). Temperature, even though it does not affect the observed total individual number, is effective on the grouping and dispersal distance of individuals. Temperature and the group are inversely proportional. As temperature decreases, individuals move and rest in the form of groups. This is likely a defense behavior against low temperatures, as individuals save energy (Gilbert et al., 2008). Groups provide a significant advantage in maintaining body temperature at low temperatures, as groups are less affected by the low temperatures. Scholander (1955) and Steen (1958) also reported that the largest groups were formed at the lowest temperatures and that the adaptive behavior depended on the temperature (at low or high temperatures). Basic behavioral types exhibited by coots outside the breeding season are swimming, feeding, and resting. These three behavioral types account for more than $80 \%$ of the activities during the day (Irwin and O'Halloran, 1997). This ratio does not change due to change in temperature. However, as 
temperature decreases, individuals show these behaviors by coming together (forming groups) and gathering in the shallow parts of the lake (Zhang et al., 2011). While grouping is a significant advantage for saving energy, gathering in the shallow parts of the lake is an important adaptation, as well. The perceived water temperature varies depending on air temperature from inland towards the coast (Bennett, 1978). Therefore, individuals gather in the coastal strip to minimize the effects of low temperature. Gathering of groups in the coastal strip during the coldest weather supports our view. As temperature rises, individuals move more freely on the lake surface and show the typical behavior (swimming, feeding, and resting) by dispersing over large areas. In this case, dispersal distance of individuals increases hence, they spread in the deeper parts of the lake as well. While group forming contributes to temperature-body heat equilibrium at low temperatures, dispersing towards the deep-cool parts of the lake at high temperatures also contributes to temperature-body heat stability. The continuous movement of individuals in the groups between the coastal strip and inwards of the lake (0-300 m) on days with highest temperatures supports our view. However, this circulation takes place individually, not in the form of groups. Protection from predators and the abundance of resources (food and enough space) is the most important determining factor in forming bird colonies (Burger, 1981). Sufficient or insufficient resources determine the intensity of competition in the group and thus the size of the group. Area and the availability of nutrients per individual minimize the competition in large lakes such as Sapanca Lake. Therefore, in this study, the individual number in the group was not observed to affect the number of groups and dispersal distance. As a result, temperature emerged as the significant factor in shaping the individual and group behavior of coots outside the breeding season. The number of individuals has no effect on their behavior or intensity of behavior due to the large habitat size.

\section{Statement of conflict of interest}

The authors declare there is no conflict of interest.

\section{REFERENCES}

Bennett, E.B., 1978. Characteristics of the thermal regime of Lake Superior. J. Great Lakes Res., 4: 310-319. https://doi.org/10.1016/S0380-1330(78)72200-8

Brent, R., Pedersen, P.F., Bech, C. and Johansen, K., 1985. Thermal balance in the European Coot Fulica atra exposed to temperature from $-28 \mathrm{C}^{\mathrm{o}}$ to $40 \mathrm{C}^{\mathrm{o}}$. Ornis Scand., 16: 145-150. https://doi. org/10.2307/3676480

Burger, J., 1981. A model for the evolution of mixedspecies colonies of Ciconiiformes. Q. Rev. Biol., 56: 143-167. https://doi.org/10.1086/412176

Cramp, S. and Simmons, K.E.L., 1980. The birds of the western Palearctic. Vol. 2. Oxford University Press, London.

Gilbert, C., Graham, R., Yvon, Le, M. and Andre, A., 2008. How do weather conditions affect the huddling behaviour of emperor penguins? Polar Biol., 31: 163-169. https://doi.org/10.1007/s00300007-0343-6

Irwin, S. and O'Halloran, J., 1997. The Wintering behaviour of Coot Fulica atra L. at Cork Lough, South-West Ireland, Biology and Environment: Proc. R. Irish Acad. A., 97B: 157-162.

Calder, W.A. and King, J.R., 1974. Thermal and caloric relations of birds, In: Avian biology (eds. D.S. Farner and J.R. King). Academic Press, New York, pp. 259-413.

Kendeigh, S.C., Dol'nik, V. R. and Gavrilov, V. M., 1977. Avian energetics, In: Granivorous bird in ecosystems (eds. J. Pinowski and S.C. Kendeigh), International Biological Programme, vol. 12. Cambridge University Press, Cambridge, pp. 127-204.

Leisler, B., 1992. Habitat selection and coexistence of migrants and Afrotropical residents, Ibis, 134: 77-82. https://doi.org/10.1111/j.1474-919X.1992. tb04754.x

McNally, R.C., 1990. The roles of floristic and physiognomy in avian community composition, Aust. J. Ecol., 15: 321-327. https://doi. org/10.1111/j.1442-9993.1990.tb01036.x

Sebastian-Gonzalez, E., Sanchez-Zapata, J.A. and Botella, F., 2010. Agricultural ponds as alternative habitat for water birds: spatial and temporal patterns of abundance and management strategies, Eur. J. Wildl. Res., 56: 11-20. https://doi.org/10.1007/ s10344-009-0288-x

Scholander, P., 1955. Evolution of climatic adaptation in the homeotherms, Evolution, 9: 15-24. https://doi. org/10.2307/2405354

Steen, J., 1958. Climatic adaptation in some small northern birds. Ecology, 39: 626-629. https://doi. org/10.2307/1931602

Zhang, W., Liu, W. and Ma, J., 2011. Territory and territorial behavior of migrating common coot (Fulica atra). J. Forest Res. Jpn., 22: 289-294. https://doi.org/10.1007/s11676-011-0164-x

Uzun, A., 2010. Bioecology of Sapanca lake (Sakarya). Sakarya Uni. Art Sci. J., 1: 1-14. 